International Journal of Applied Dental Sciences 2021; 7(2): 323-327

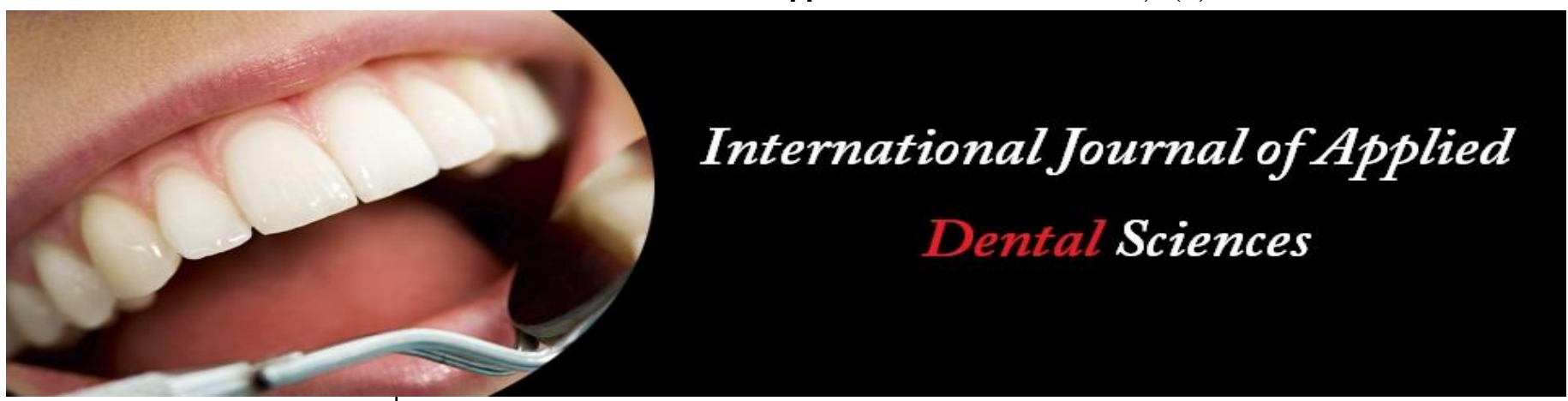

ISSN Print: 2394-7489

ISSN Online: 2394-7497

IJADS 2021; 7(2): 323-327

(C) 2021 IJADS

www.oraljournal.com

Received: 25-02-2021

Accepted: 27-03-2021

\section{Adrian Flores-Ibarra}

Master in Sciences Student,

Universidad Autonoma de Nuevo

Leon, Facultad de Odontologia,

Monterrey, Nuevo Leon, CP 64460 ,

Mexico

Maria Concepcion Trevinño-Tijerina Professor, Universidad Autonoma de Nuevo Leon, Facultad de

Odontologia, Monterrey, Nuevo Leon, CP 64460, Mexico

Juana Nelly Leal-Camarillo Associate Professor, Universidad Autonoma de Nuevo Leon, Facultad de Odontologia, Monterrey, Nuevo Leon, CP 64460, Mexico

Christian Starlight Franco Trejo Professor, Universidad Autonoma de Zacatecas, Ciencias de la Salud, Unidad Academica de Medicina Human y Ciencias de la Salud, Zacatecas, Mexico

Ana Karen Gonzalez Alvarez Professor, Universidad Autonoma de Zacatecas, Ciencias de la Salud, Unidad Academica de Odontologia, Zacatecas, Mexico

Rosa Isela Sanchez-Najera Professor, Universidad Autonoma de Nuevo Leon, Facultad de

Odontologia, Monterrey, Nuevo Leon, CP 64460, Mexico

Juan Manuel Solis-Soto Professor, Universidad Autonoma de Nuevo Leon, Facultad de Odontologia, Monterrey, Nuevo Leon, CP 64460, Mexico

Corresponding Author: Adrian Flores-Ibarra

Master in Sciences Student, Universidad Autonoma de Nuevo Leon, Facultad de Odontologia, Monterrey, Nuevo Leon, CP 64460 Mexico

\section{Ectodermal dysplasia, an odontological point of view}

\author{
Adrian Flores-Ibarra, Maria Concepcion Trevinño-Tijerina, Juana Nelly \\ Leal-Camarillo, Christian Starlight Franco Trejo, Ana Karen Gonzalez \\ Alvarez, Rosa Isela Sanchez-Najera and Juan Manuel Solis-Soto
}

DOI: https://doi.org/10.22271/oral.2021.v7.i2e.1228

Abstract

Introduction: Ectodermal dysplasia (ED) consists of rare genetic disorders in which it is mainly characterized by abnormalities of tissues derived mainly from the ectoderm, sometimes tissues of mesodermal origin. It has a frequency of one in 17,000 births, mainly males.

Objective: To analyze the literature on ectodermal dysplasia and its application in dentistry. To investigate information on etiology, genetics, general and oral manifestations, and its treatment.

Methodology: A research search was carried out in PubMed, PMC and Google Scholar with the words "ectodermal dysplasia", "genetics", "oral manifestations", "treatment" and "clinical manifestations".

Results: The factor of ED was found to be of genetic origin. The mutations are X-linked. The most affected structures are the skin, hair and nails; this is due to its ectodermal origin. The oral manifestations can appear in the shape of the teeth, size, number of teeth present and can even affect the normal development of the alveolar ridge. The use of removable prosthesis and the placement of implants are the most applied treatments to improve the conditions of the patients.

Conclusions: The most affected structures are those of ectodermal origin; while in the oral cavity we can present a partial absence of the dentition, together with alterations of the alveolar bone structures and even patients can come to suffer from cleft palate and cleft lip. There is no specific treatment, but to treat the affections presented by means of implants and prosthesis.

Keywords: ectodermal dysplasia, etiology, treatment

\section{Introduction}

Ectodermal dysplasia (ED) is composed of a group of rare genetic disorders characterized mainly by abnormalities of tissues derived primarily from the ectoderm, such as hair, teeth, skin, sweat glands, and nails, along with occasional dysfunction of tissues of mesodermal origin ${ }^{[1,2]}$. Performing some treatment to correct their condition during infancy may have better results than one applied at a later stage of development. Prosthetic treatment, either fixed with implants or removable, is the most frequent treatment in these patients, so there should be good planning for better results ${ }^{[3]}$.

The literature has found 345 reported cases with ED, of which 206 are mainly due to EDA gene mutations. In 2017, the HGMD Professional 2017 gene mutation database recorded 314 mutations in the EDA gene ${ }^{[4]}$. So, we have that the most frequent type of mutation consists of substitutions occurring in a single base pair in coding regions. There are many different types of ectodermal dysplasias; each type of dysplasia is caused by a specific mutation in some genes. The most common phenotypes of dysplasia are of the anhidrotic or hypohidrotic type (HED known as Christ-Siemens-Touraine Syndrome/ EDA known as Clouston Syndrome); this disorder is X-linked, which has a frequency of one in 17,000 live births in the general populat ion ${ }^{[1,5]}$

Studies have found that ED manifests mainly by upper maxillary retrusion caused by underdevelopment, will have a forward and upward displacement of the lower jaw and a collapsed anterior facial height; while the palatal arch usually presents in a high manner and a cleft palate may be present. The patient usually presents an absence of teeth caused by poor alveolar bone growth, as well as hypodontia and anodontia ${ }^{[5,6,7]}$, so it is here when the dentist challenges his skills and employ some treatment. 
Nowadays there is a great lack of attention to patients with disabilities, some of them are born with these disabilities and some others acquire them during life; there comes a time for the dentist that becomes a great challenge in the care of these patients, such is the case of patients with Ectodermal Dysplasia. ED is a syndrome that will have many manifestations in the face and mouth, among other conditions, so the main objectives of this research was to investigate information about the etiology, genetics, the way it manifests and the treatment plan.

\section{Materials and Methods}

Articles on the subject published through the PubMed, SCOPUS and Google Scholar databases were analyzed, with emphasis on the last 5 years. The quality of the articles was evaluated using PRISMA guidelines, i.e., identification, review, choice and inclusion. The quality of the reviews was assessed using the measurement tool for evaluating systematic reviews (AMSTAR-2) ${ }^{[8]}$. The search was performed using Boolean logical operators AND, OR and NOT. It was realized with the words "genetics", "ectodermal dysplasia", "oral manifestations", "treatment" and "clinical manifestations".. The keywords were used individually, as well as each of them related to each other.

\section{Results \& Discussion \\ 3.1 Etiology}

ED has a great multisystemic involvement, which will cause certain alterations in the structures of ectodermal origin; it not only affects this structure, but can also compromise the mesoderm, of genetic origin. In the literature we can find that the ectoderm and endoderm are present at the end of the first week after fertilization, while the mesoderm will form in the third week, where it is formed by the product of the invagination of the ectoderm. The ectoderm will give rise to the central and peripheral nervous system, tooth enamel, sebaceous and sweat glands and the epithelium of organs ${ }^{[1,9]}$. The incidence of the different EDs can vary, but is estimated at 7:10 000 live births ${ }^{[10]}$. There are about 150 different variants of ED described in the literature. The most frequent is $\mathrm{X}$-linked recessive inheritance; this disease tends to manifest mainly in males ${ }^{[10,11-14]}$. The first recorded cases of ED were reported in the year 1792, since that time various characteristic signs related to dysplasia have been identified. Generally, the manifestations can affect the person in all senses; there are social problems that can have an impact on the quality of life of the individual ${ }^{[7]}$

ED can also be initiated by autosomal mutations, where those of the EDA1 gene have been found to be responsible for $58 \%$ of cases. The condition will be delineated into two forms mainly, known as (HED) hypohidrotic or anhydrotic (ChristSiemens-Touraine syndrome) where endocrine glands are absent or markedly diminished and hydrotic (Clouston syndrome) with normal endocrine glands. The two types show similarities in the involvement of teeth and hair, although the nails and sweat glands show a different pattern ${ }^{[2,15,16]}$. HED is the most frequent of all dysplasias and brings with it hypodontia, hypohidrosis and hypotrichosis and presents an infant mortality rate between 2 and $20 \%$, all this is going to depend on the precocity of diagnosis and treatment protocols $[4,11-13,17,18]$. Anhidrotic ectodermal dysplasia is considered another classification of these dysplasias, which consists of sparse hair, dental hypoplasia and anhidrosis ${ }^{[14]}$.

Ectodermal dysplasia is of genetic origin and has generally been found to affect mainly the ectoderm and sometimes the mesoderm; it is mainly due to autosomal mutations. It encompasses a wide variety of types, where the hypohidrotic and hydrotic types are the most frequent, appearing mainly in males.

\subsection{Genetics}

$\mathrm{ED}$ is mainly due to maldevelopment of ectodermal derivatives in embryonic life. X-linked hypohidrotic ED has been mapped to the long arm of the Xq-12-q13.1 band [14, 1922]. We found that $60 \%$ to $80 \%$ of women have some degree of hypodontia. Prenatal testing would be possible for pregnant women at increased risk if pathogenic variants in the family were known ${ }^{[14,23]}$.

In some studies, genetic testing marked a mutation of the EDA gene c.911A $\rightarrow$ G. Also in Y304 mediated, trimerization of EDA and cysteine replacement was found to abrogate protein secretion. A pregnancy with two male sex twins was shown on ultrasonographic examination without dental germs ${ }^{[24]}$. ED is also caused by mutation in the PKP 1 gene and this form is characterized by generalized skin fragility, alopecia, nail dystrophy, plantar palmar dystrophy and painful fissures ${ }^{[25]}$. In other studies, a Val472Glyfs 28 mutation was found, where there is not much information, but it leads to premature protein termination ${ }^{[26]}$.

The most frequent presentation of HED is caused by pathogenic variants of the EDA gene in Xq13.1. This gene tends to encode ectodysplasin, which is usually a molecule involved in epithelial-mesenchymal communication during the skin development process. Other genes that can be associated with this dysplasia are the EDAR, EDARADD and WNT10A genes, where it will present a recessive or dominant inheritance pattern ${ }^{\text {[16, 27-29]. }}$.

Studies have shown that the hypohidrotic subtype is X-linked. Pathogenic variants in the EDA gene have been found to exist in Xq13.1, EDAR, EDARADD and WNT10A.

\subsection{General manifestations}

Some specific signs will be present in certain areas of the body such as skin, hair and nails. The peri skin may even show fine wrinkling with some hyperpigmentation and hypoplasia in the midface, highlighting protruding lips. It has also been found that the nails may also have a dystrophic and brittle appearance ${ }^{[25,26,30]}$.

Studies have been found, where affected individuals with the hypohidrotic form often show heat intolerance due to a reduced number of sweat glands and this in turn results in a mortality rate of approximately $30 \%$ in early childhood if the disease is not properly diagnosed and treated ${ }^{[4,13,31]}$. They also tend to present with asymmetric development of the alveolar ridge, changes in nasal secretions from concretions that are solidified secretions in the ducts, a depressed nasal bridge, decreased sebaceous secretions, some dry eye symptoms, fragile appearing skin, a lack of dermal ridges, persistent peri-orbital hyperpigmentation, pneumonia and some asthma-like symptoms related to abnormal bronchial glands, hoarse voice, mid-facial hypoplasia. While physical growth and psychomotor development are within normal limits ${ }^{[23]}$.

These patients usually present with dysmorphic features, oligodontia, friable scaly skin, hypoplastic sebaceous glands where they exhibit decreased sweating, hypoplastic salivary glands exhibiting dry oral mucosa and hypoplastic glands. Generally, these patients are vulnerable to allergic diseases such as bronchial asthma, allergic rhinitis, food allergy, pneumonia, otitis media, among others ${ }^{[2]}$. Oligodontia tends 
to result in decreased oral intake, causing poor nutrition and reduced tears leading to corneal erosion ${ }^{[14]}$.

Most of the subtypes of this disease present the same signs and symptomatology, the most affected structures are the skin, hair, nails; this is because it is of ectodermal origin. It is important to employ early diagnosis as well as treatment because sometimes the conditions can increase the mortality rate at an early age.

\subsection{Oral manifestations}

The most common oral manifestations include anodontia, hypodontia, retained teeth, loss of vertical dimensions of occlusion, deformed teeth, deficient alveolar growth, prominent lips ${ }^{[1,2,27,32,33]}$.

It has been found that central incisors, canines and first molars in the maxilla and in the mandible are the canines, first premolars and molars are the pieces that present the highest percentage; with less probability we find the anterior teeth ${ }^{[1]}$. The absence of teeth can result from poor development of the alveolar bone. Some patients may also present cleft lip and palate ${ }^{[34]}$.

Regarding the shape and size of the teeth, they are usually small in size, conical, bulbous or taurodontic in shape and usually have a large space between each tooth. Studies have shown that enamel is prone to decay and mechanical damage. Sometimes atrophic inflammation of the mucosa of the oral cavity, hoarse voice and difficulty in swallowing may be present ${ }^{[5]}$. Defects in the number of teeth is a very common problem in these dysplasias. Third molars usually do not develop in $25 \%$ of the world's population. The number of teeth can range from more than a dozen, through several, or the lack of all permanent teeth and even, in some cases the lack of both dentitions is present $[4,31,35,36]$. Studies have found that the most frequent missing teeth are the upper lateral incisors, upper and lower premolars ${ }^{[37]}$.

The oral manifestations can occur in the shape of the teeth, size, the number of teeth present and can even affect the normal development of the alveolar ridge, making it a challenge when planning treatment, because the bone can compromise the results.

\subsection{Treatment}

There is no definitive pharmacologic treatment for ectodermal dysplasia. Patients are usually treated depending on the ectodermal structures affected ${ }^{[38]}$.

Dental care through prosthetic rehabilitation at an early age can help children with ED develop speech, chewing and swallowing skills, along with improved facial support ratio and temporomandibular joint function ${ }^{[23,34,39]}$.

The union of teeth that present a conical shape in young individuals will improve esthetics and chewing ability. Sometimes it is necessary to use treatments such as orthodontics and dental implants; it has been shown that implants in the anterior portion of the mandibular arch have had very good results in children when they are treated at an early age, while in adults the aim is to obtain good esthetics and a functional appliance. There is also a tendency to implement therapies aimed at oral lubrication and caries control $[2,23,39,40]$. Other treatments that can be applied are bone grafts in sinus lift procedures, in the placement of implants and any other treatment that can be used to align the dentition by orthodontics ${ }^{[41]}$. The use of light clothing, air conditioning for the environment, both at home and in the office, a cold-water atomizer, use of artificial tears and application of petroleum jelly for mucosal protection in these patients is recommended ${ }^{[42]}$.

Prostheses ranging from fixed prostheses, removable prostheses, implant-retained prostheses, implant-supported prostheses or some other combination depending on the degree of disease of the patient can be used. The application of removable prostheses with numerous retention clasps is recommended to ensure a good development of the prosthetic base bone structure. Adaptation is usually necessary because of the bony structural changes in the base, together with the shape of the few remaining teeth in the dental arch. The use of a tin foil is recommended to protect the dry oral mucosa from the traumatic impact of plaque, along with the application of good hygiene technique to the patient $[4,18]$. Treatment planning should be carried out and treatment should be started as soon as possible after diagnosis, all this is in order to have good control in terms of esthetic, functional and psychological aspects; so that we can have control in the different stages and improve the quality of life of patients ${ }^{[2}$, 10].

Before treatment with Covid-19, complete isolation is recommended, hospital visits should only be for emergencies, good hand washing with disinfection is very important, but the risks of using these products that may cause dermatologic damage should be taken into account ${ }^{[43]}$.

It is essential to start treatment as soon as possible to prolong the patient's life and give him/her a better quality of life. It is a challenge when deciding to start therapy because patients tend to suffer from deformities in the oral cavity. The use of removable prosthesis and the placement of implants are the most applied treatments to improve the patients' conditions.

\section{Conclusions}

Ectodermal dysplasia has an incidence of 7 persons per 10000 born and its origin is genetic. The most affected structures are the skin, hair, nails; while in the oral cavity we can present a partial absence of the dentition, along with alterations of the structures of the alveolar bone and even patients may suffer from cleft palate and cleft lip. As for the treatment for dysplasia, there is no established treatment, it is only to give attention to the alterations caused by dysplasia. The use of dental implants and prosthesis at an early age has favored the life span of patients.

\section{References}

1. Rodríguez M. Etiología, manifestaciones clínicas y estudio por imágenes de la displasia ectodérmica: Una revisión de la literatura. Rev Cient Odontol (Lima). 2018;6(2):236-247.

2. Hasan S, Govind M, Sawai MA, Ansari MD. Hypohidrotic ectodermal dysplasia with autosomal recessive inheritance pattern: Report of a rare and unusual case with a brief review of literature. J Oral Maxillofac Pathol 2019;23(3):479.

3. Gholman RR, Kassar WM, El Meligy OA. Rehabilitación dental de un niño con displasia ectodérmica: informe de un caso. Int J Clin Pediatr Dent 2019;12(4):362-365.

4. Trzeciak WH, Koczorowski R. Molecular basis of hypohidrotic ectodermal dysplasia: an update. J Appl Genet 2016;57(1):51-61.

5. Reyes J, Mendoza MI, Garrido E, Méndez CF, Méndez AR, Pozo G. Hypohidrotic ectodermal dysplasia: clinical and molecular review. Int J Dermatol 2018;57(8):965972

6. Kumar NM, Srinivas P, Ramadevi S, Prasad SR, Ajaykumar P, Sudhakar M. Hypohidrotic ectodermal 
dysplasia with anodontia: A rare case-rehabilitation by prosthetic management. J Indian Acad Oral Med Radiol 2012;24:342-5.

7. Ramírez M, Jaimes L, Pieruccini JF, Rodríguez MJ. Displasia ectodérmica: Un reporte de caso. Rev. Estomatol. Herediana 2016;26(3):162-167.

8. Shea BJ, Reeves BC, Wells G, Thuku M, Hamel C, Moran J et al. AMSTAR 2: A critical appraisal tool for systematic reviews that include randomised or nonrandomised studies of healthcare interventions, or both. BMJ 2017;21;358: j4008.

9. Savasta S, Carlone G, Castagnoli R, Chiappe F, Bassanese F, Piras R et al. X-linked hypohidrotic ectodermal dysplasia: new features and a novel EDA gene mutation. Cytogenet Genome Res 2017;152:111-6.

10. Queiroz KT, Novaes TF, Imparato JC, Costa GP, Bonini GC. The role of the dentist in the diagnosis of ectodermal dysplasia. RGO Gaúcha J Dent 2017;65:161-7.

11. Callea M, Yavuz I, Clarich G, Cammarata-Scalisi F. Estudio clínico y molecular en un escolar con displasia ectodérmica hipohidrótica ligada al X [Clinical and molecular study in a child with X-linked hypohidrotic ectodermal dysplasia]. Arch Argent Pediatr. 2015;113(6):e341-4.

12. Dolmo E, Pineda M, Cabellero H. Hypohydrotic ectodermal dysplasia: Report of case. Acta Pediátrica Hondureña 2017;7(2):651-652.

13. Chappidi V, Voulligonda D, Bhogavaram B, Reddy PK. Ectodermal dysplasia: Report of two cases in a family and literature review. J Family Med Prim Care. 2019;8(3):1263-1265.

14. Suzuki T, Tajima H, Migita M, Pawankar R, Yanagihara T, Fujita A et al. A case of anhidrotic ectodermal dysplasia presenting with pyrexia, atopic eczema, and food allergy. Asia Pac Allergy 2019;14;9(1):e3.

15. Arif T, Adil M, Amin SS, Dorjay K. Autosomal recessive anhidrotic ectodermal dysplasia: A rare disease. Indian J Paediatr Dermatol 2018;19:84-6.

16. Wang X, Zhang Z, Yuan S, Ren J, Qu H, Zhang G et al. A novel EDA1 missense mutation in $\mathrm{X}$-linked hypohidrotic ectodermal dysplasia. Medicine (Baltimore) 2020;99(11):e19244.

17. Shawky RM, Gamal R. Christ-Siemens-Touraine syndrome with cleft palate, absent nipples, gallstones, and mild mental retardation in an Egyptian child. Egypt $\mathbf{J}$ Med Hum Genet 2016;17:389-95.

18. Lam P, Nguyen N, Cao D. Dental management of ectodermal dysplasia: Removable prosthodontics, endosseous implants or subperiosteal implants - A case report. Int J Oral Maxillofac Surg 2017;46:97-8.

19. Joseph S, Cherackal GJ, Jacob J, Varghese AK. Multidisciplinary management of hypohydrotic ectodermal dysplasia - a case report. Clin Case Rep 2015;3(5):280-6.

20. Wohlfart S, Meiller R, Hammersen J, Park J, MenzelSevering J, Melichar VO et al. Natural history of Xlinked hypohidrotic ectodermal dysplasia: a 5-year follow-up study. Orphanet J Rare Dis 2020;15:1-11.

21. Zeng B, Xiao X, Li S, Lu H, Lu J, Zhu L et al. Eight Mutations of Three Genes (EDA, EDAR, and WNT10A) Identified in Seven Hypohidrotic Ectodermal Dysplasia Patients. Genes (Basel) 2016;7(9):65.

22. Gaczkowska A, Abdalla EM, Dowidar KM, Elhady GM, Jagodzinski PP, Mostowska A. De novo EDA mutations: variable expression in two Egyptian families. Arch Oral
BiolArch Oral Biol 2016;68:21-28.

23. Wright T, Grange D, Richter M. Hypohidrotic ectodermal dysplasia. Adam MP, editor. Gene reviews. Seattle: University of Washington 2019.

24. Schneider H, Faschingbauer F, Schuepbach-Mallepell S, Körber I, Wohlfart S, Dick A et al. Prenatal Correction of $\mathrm{X}$-Linked Hypohidrotic Ectodermal Dysplasia. N Engl J Med 2018;378(17):1604-1610.

25. McGrath JA, McMillan JR, Shemanko CS, Runswick SK, Leigh IM, Lane EB et al. Mutations in the plakophilin 1 gene result in ectodermal dysplasia/skin fragility syndrome. Nat Genet 1997;17(2):240-4.

26. Alatas ET, Kara A, Kara M, Dogan G, Baysal O. Ectodermal dysplasia-skin fragility syndrome with a new mutation. Indian $\mathbf{J}$ Dermatol Venereol Leprol. 2017;83(4):476-479.

27. Gomes MF, Sichi LGB, Giannasi LC. Phenotypic features and salivary parameters in patients with ectodermal dysplasia: report of three cases. Case Rep Dent 2018, 2409212

28. Martínez MC, Ballesta MJ, López V, Sánchez MJ, Serrano AT, Barreda M et al. EDA, EDAR, EDARADD and WNT10A allelic variants in patients with ectodermal derivative impairment in the Spanish population. Orphanet J Rare Dis 2019;14:1-10.

29. Noriega MA, García C, Villaseñor A, Mena CA, Toledo M, Valencia A et al. Displasia ectodérmica hipohidrótica ligada al cromosoma $\mathrm{X}$ de novo por variante recurrente en un paciente mexicano. Bol. Med. Hosp. Infant. Mex 2020;77(4):212-217.

30. Ohno K, Ohmori I. Anodontia with hypohidrotic ectodermal dysplasia in a young female: A case report. Pediatr Dent 2000;22:49-52.

31. Clarke A, Phillips DI, Brown R, Harper PS. Clinical aspects of X-linked hypohidrotic ectodermal dysplasia. Arch Dis Child 1987;62(10):989-96.

32. Bergendal B. Orodental manifestations in ectodermal dysplasia-a review. Am J Med Genet 2014;164A:246571.

33. Nallanchakrava $S$, Nallanchakrava S. Oral rehabilitation of a patient with ectodermal dysplasia with prosthodontics treatment. Indian $\mathbf{J}$ Dermatol 2013;58(3):241.

34. Ou-Yang LW, Li TY, Tsai AI. Early prosthodontic intervention on two three-year-old twin girls with ectodermal dysplasia. Eur J Paediatr Dent. 2019;20(2):139-142.

35. De Coster PJ, Marks LA, Martens LC, Huysseune A. Dental agenesis: genetic and clinical perspectives. J Oral Pathol Med 2009;38(1):1-17.

36. Nieminen P. Genetic basis of tooth agenesis. J Exp Zool B Mol Dev Evol 2009;312B(4):320-42.

37. Anbouba GM, Carmany EP, Natoli JL. The characterization of hypodontia, hypohidrosis, and hypotrichosis associated with X-linked hypohidrotic ectodermal dysplasia: A systematic review. Am J Med Genet 2020;182(4):831-841.

38. Bari AU, Rahman SB. Hypohidrotic ectodermal dysplasia: A case report and literature review. J Pak Assoc Dermatol. 2007; 17:52-5.

39. Kramer FJ, Baethge C, Tschernitschek H. Implants in children with ectodermal dysplasia: A case report and literature review. Clin Oral Implants Res. 2007;18(1):140-6.

40. Abdulla AM, Almaliki AY, Shakeela NV, Alkahtani Z, 
Alqahtani MA, Sainudeen $\mathrm{S}$ et al. Prosthodontic Management of a Pediatric Patient with Christ-SiemensTouraine Syndrome: A Case Report. Int J Clin Pediatr Dent 2019;12(6):569-572.

41. Majmundar VD, Baxi K. Ectodermal Dysplasia. In: StatPearls. Treasure Island (FL) 2020.

42. Dhanrajani PJ, Jiffry AO. Management of ectodermal dysphasia: a literature review. Dent Update 1998;25:7375.

43. Callea M, Willoughby CE, Perry D, Holzer U, Fedele G, Tadich AC, et al. COVID-19 and ectodermal dysplasias. Recommendations are necessary. Dermatol Ther. 2020, e13702. 